\title{
Low Dose Total Body Irradiation (600 cGy) as a Conditioning Regimen in Allogenic Hematopoietic Stem Cell Transplant in Children with Acute Lymphoblastic Leukemia
}

\author{
Alberto Olaya-Vargas ${ }^{1 *}$, Martín Pérez-García ${ }^{2}$, Nideshda Ramírez-Uribe², \\ M. Angeles Del Campo-Martinez², Gerardo Lopez-Hernández ${ }^{2}$, \\ Montserrat Hernández-García ${ }^{3}$, Jorge Amador-Zarco ${ }^{4}$, Guadalupe Garcia-Vega4, \\ Yadira Melchor-Vidal5, Marta Zapata-Tarres', Rocío Cárdenas-Cardos6, \\ Roberto Rivera-Luna? \\ ${ }^{1}$ Hematopoietic Stem Cell Transplant Unit (HSCTU) from Pediatric National Institute (INP), Mexico City, Mexico \\ ${ }^{2}$ Pediatric Bone Marrow Transplant Program at the HSCTU INP, Mexico City, Mexico \\ ${ }^{3}$ Pediatric Bone Marrow Transplant Program at the HSCTU-HITO Hospital, Mexico City, Mexico \\ ${ }^{4}$ Radiotherapy Department, INP, Mexico City, Mexico \\ ${ }^{5}$ Pediatric Bone Marrow Transplant Program at the HSCTU-ABC Medical Center, Mexico City, Mexico \\ ${ }^{6}$ Department of Pediatric Oncology from the INP, Mexico City, Mexico \\ ${ }^{7}$ Division of Pediatric Hem/Oncology from the INP, Mexico City, Mexico \\ Email: "alberto.olaya@yahoo.com.mx
}

Received 12 July 2016; accepted 7 August 2016; published 10 August 2016

Copyright (C) 2016 by authors and Scientific Research Publishing Inc.

This work is licensed under the Creative Commons Attribution International License (CC BY). http://creativecommons.org/licenses/by/4.0/

(c) () Open Access

\section{Abstract}

Total body irradiation (TBI) is conditioning regimen in children with acute lymphoblastic leukemia (ALL) with a very high risk of relapse or in those who have not achieved remission and have relapsed and subsequently received allogenic hematopoietic stem cell transplantation (HSCT). A retrospective evaluation of 33 ALL patients in full remission with an indication of HSCT was performed to evaluate overall survival (OS) and event-free survival (EFS). The inclusion criteria included a myeloablative conditioning regimen of TBI at a dose of $600 \mathrm{cGy}$. The observed OS at 5 years was $50 \%$, and the EFS of $32 \%$ we observed difference in the EFS stem cell origin; the peripheral blood (PB) 60\%, and the umbilical cord blood (UC) accounted for 40\%. Overall, $45 \%$ had a documented chimerism. The OS at 5 years from patients with chimeras was $75 \%$, while those

${ }^{*}$ Corresponding author.

How to cite this paper: Olaya-Vargas, A., Pérez-García, M., Ramírez-Uribe, N., Del Campo-Martinez, M.A., Lopez-Hernández, G., Hernández-García, M., Amador-Zarco, J., Garcia-Vega, G., Melchor-Vidal, Y., Zapata-Tarres, M., Cárdenas-Cardos, R. and Rivera-Luna, R. (2016) Low Dose Total Body Irradiation (600 cGy) as a Conditioning Regimen in Allogenic Hematopoietic Stem Cell Transplant in Children with Acute Lymphoblastic Leukemia. Journal of Cancer Therapy, 7, 586-592. 
without chimeras had an $O S$ at 5 years of $25 \%$. The mortality in the first 100 days was $24 \%$. A total of $24.2 \%$ of children presented with acute graft versus-host disease (GVHD), while $33 \%$ had chronic GVHD. Currently, there is no general agreement among all international centers regarding the optimum TBI dose. Our study reports an acceptable range of adverse events with a relatively low dose of $600 \mathrm{cGy}$.

Keywords

Total Body Irradiation, Stem Cell Transplantation

\section{Introduction}

Acute lymphoblastic leukemia (ALL) is the most common malignancy of childhood cancer in Mexico [1]-[4]. Despite the current knowledge in the biology of this disease and modern chemotherapy treatments, a number of children will eventually have to submit to hematopoietic stem cell transplantation (HSCT) [1].

The 5-year overall survival (OS) for ALL is reported to be 75\% or more [1] [5]-[9].

However, when these patients relapse, particularly during treatment with conventional chemotherapy regimens, the rate of survival diminishes significantly [10]-[12]. Therefore, it is accepted that these patients could benefit from allogeneic HSCT [5] [8] [13] [14].

The importance of HSCT resides in the conditioning regimen used, as well as in the desired effect of the graft versus leukemia, which maintains these patients under remission without the need of maintenance chemotherapy. Total Body Irradiation (TBI) plays an essential role in conditioning regimens [15]-[18].

The essential role of TBI in ALL represents part of the multidisciplinary treatment in children who had to submit to HSCT. The classical concept of using TBI as a conditioning regimen continues to be very useful. The basic mechanism of action when this procedure is used lies in the eradication of residual leukemic cells, particularly those in sanctuary sites such as testicles and the central nervous system, as well as its action on chemotherapy-resistant leukemic clones [10] [19] [20], consequently favoring the graft effect.

The use of TBI is essential as a primary part of the conditioning regimen in ALL; however, the dose causes controversy [21]-[23]. The most common conventional dose is 1200 cGy [1] [7]. However, the adverse events (AEs), including growth and development alterations, as well as hormonal dysfunctions, are very common [2] [3] [7] [12] [21]. Different doses of TBI have been evaluated [7] [24] [25] such reports. Have documented that fractioned doses produce a better rate of response and fewer adverse effects. The purpose of the current work was to report the experience of a National Institute of Health at Mexico City with 33 consecutive pediatric ALL patients in complete remission and who had to submit to HSCT, using a myeloablative conditioning regimen including TBI at a dose of 600 cGy plus chemotherapy.

\section{Material and Methods}

The inclusion criteria for the study comprised patients registered at the Pediatric National Institute of Mexico (INP) from December 2006 to June 2010 with ALL who achieved complete remission and were classified as high-risk ALL.

Basic clinical characteristics were considered. The current study was approved by the Institutional Review Board and Ethical Committee, in each of the patients the parents signed a consent form for the entire treatment.

The treatment included the conditioning regimen with TBI at a dose of 600 cGy in 3 fractions (200 cGy every day per three days, from day -7 to -5 ), chemotherapy with cyclophosphamide $60 \mathrm{mg} / \mathrm{kg} / \mathrm{day}$, from day -4 to -3 , and etoposide $1200 \mathrm{mg} / \mathrm{m}^{2}$ on day -2 . Day -1 the patient received no chemotherapy, and on day 0 the hematopoietic stem cells were infused intravenously through a central catheter.

\section{Statical Analysis}

A descriptive analysis was performed using Student's T test and bi-variate analysis with logistic regression. Data for survival were recorded according to the last follow-up or date of death. The overall survival (OS) and event-free survival (EFS) were evaluated using the Kaplan-Meier life probability method. The EFS was adjusted 
by the Cox test.

All analyses were performed using the statistical package SPSS 15 and zapmeta.mx/statistical software

\section{Results}

A total of 33 patients who qualified the inclusion criteria were included in the analysis; 24 (74\%) were males, and 9 (27\%) were females. The median patient age was 11 years. A total of $24.4 \%$ received HSCT on first remission, $51 \%$ on second remission, $18 \%$ on third and $6 \%$ on fourth. The mean follow-up was 521 days (range: 8 to 16 days following transplantation).

The type of HSCT performed was peripheral blood (PB) 39.3\%, umbilical cord (UC) blood $57.5 \%$ and bone marrow (BM) $3 \%$. The mean CD34+ progenitor cell numbers was $5.82 \times 10^{6} / \mathrm{kg}, 2.88 \times 10^{5} / \mathrm{kg}$ and $3.6 \times 10^{5} / \mathrm{kg}$, for PB, UC and BM, respectively (Table 1).

Overall survival and disease-free survival in nineteen patients who underwent HSCT with chemotherapy plus TBI with 600 cGy presented an OS of 57.5\% (Figure 1(a)), while the event-free survival was 32\% (Figure $1(\mathrm{~b}))$.

Fourteen (42.2\%) patients died, and the overall transplant-related mortality was $24 \%$. Overall, $64.2 \%$ (9 patients) died of other causes, of which infection was the most frequent, occurring in 6 patients. The other causes not associated with relapse were hematologic toxicity and chronic graft-versus-host disease. There were 5 (35.7\%) patients whose mortality was due to relapse; among this group, 8 deaths (88\%) occurred within the first 100 days after transplantation.

Ten (30.3\%) patients presented relapse. Eight patients had BM relapse, one had isolated central nervous system (CNS) relapse, and one presented with combined relapse (CNS and BM). The range of time to relapse was between 2 and 26 months after the transplant, with a mean of time to relapse of 10.3 months.

Nineteen patients (57.5\%) are alive, 14 (42.4\%) had remission. Survival according the cell source was analyzed, with the source of bone marrow being greater. However, it is important to note that only 1 of the 33 patients included in the series was transplanted from this source $(\mathrm{p}=0.26)$. The PB source had a cumulative survival of $60 \%$ and that of the UC was $40 \%$ (Figure 2). Of the 14 patients who died, $71.4 \%$ (10 patients) received $\mathrm{UC}$ as the cell source and $28 \%$ (4 patients) received PB ( $\mathrm{p}=0.32)$.

\subsection{Chimerism and a Graft Failure}

The mean myeloid graft was 17.6 days, and chimerism was observed at the time of graft in $54.8 \%$. Regarding the cell source, chimerism was negative in $72.2 \%$ of UCB and $8.3 \%$ of PB ( $p=0.002)$. The chimerism was held at $45.1 \%$ at 100 days; $16 \%$ corresponded to UCB and $83 \%$ to PB. The patients who received BM began to lose chimera at day $+90(\mathrm{p}=0.001)$. Two of the patients transplanted with UCB that had primary graft failure underwent a second transplant (maternal haploidentical), achieving full graft. However, one presented loss of chimerism and relapse to BM.

Table 1. Analysis of 33 patients submitted to stem cell transplant.

\begin{tabular}{cc}
\hline Characteristics & $\mathrm{n}$ \\
\hline Mean age & 11 years \\
Gender: & \\
Female & 9 \\
Male & 24 \\
Remission-number: & \\
First complete remission & 8 \\
Second complete remission & 17 \\
Third complete remission & 6 \\
Fourth complete remission & 2 \\
CD 34 cells source: & \\
Cord blood & 19 \\
Peripheral blood & 13 \\
Bone marrow & 1 \\
\hline
\end{tabular}




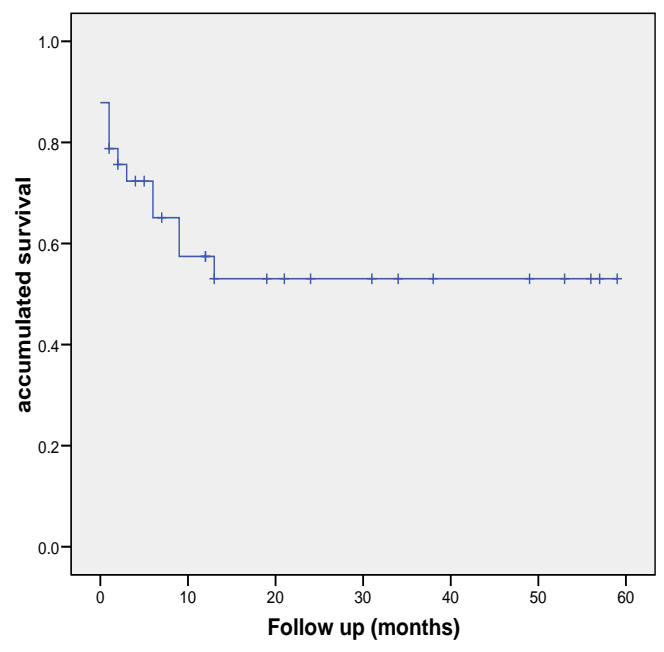

(a)
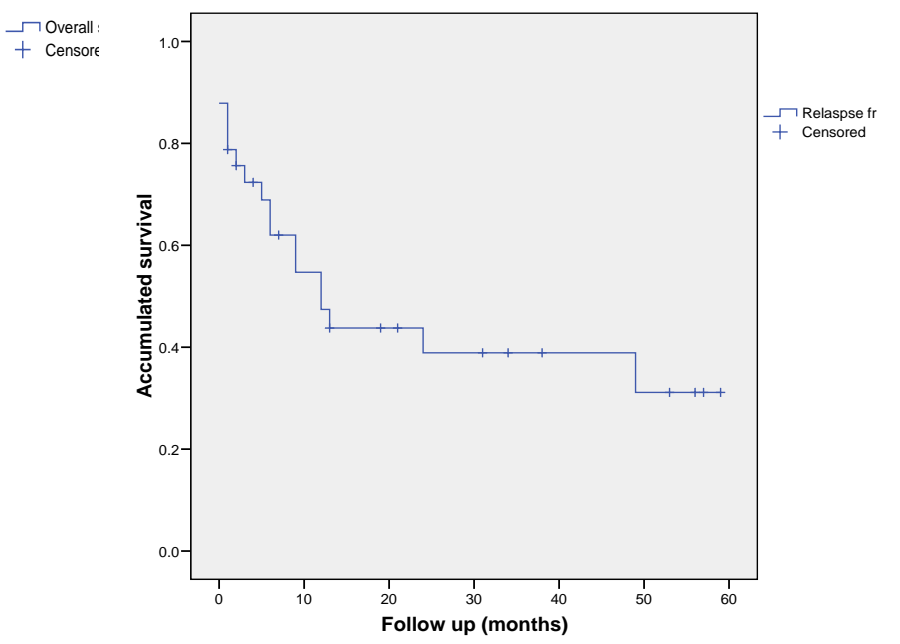

(b)

Figure 1. Overall Survival according to cell source. (a) Overall survival in children with HSCT and conditioning with radiation 600 cGy; (b) Event-free survival in children with HSCT and conditioning with radiation 600 cGy.

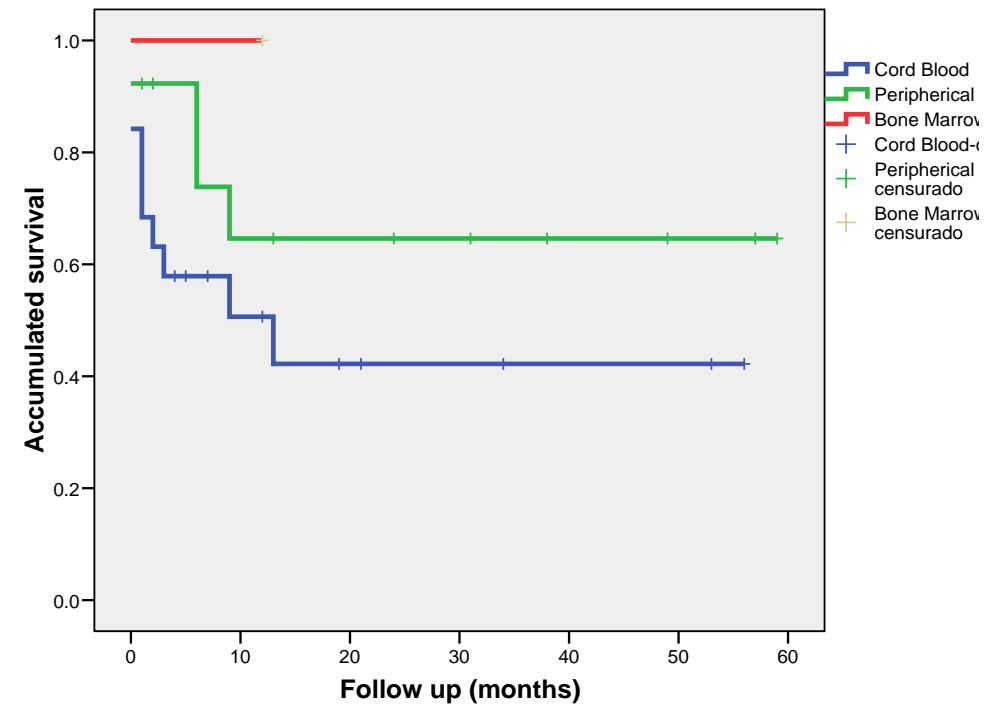

Figure 2. Overall survival in children undergoing HSCT with 600 cGy radiotherapy conditioning according to cell source.

The OS of patients who had complete donor chimerism was 75\%, and 25\% for those negative to chimerism (p $=0.005)$. For patients with sustained chimerism ( $>100$ days $)$, the OS was $78 \%(p=0.006)$.

\subsection{Acute versus Chronic Graft-versus-Host Disease}

Eight of the thirty-three transplanted patients presented acute GVHD; 4 of them were Grade II, 2 were grade III, and 3 were grade IV. The area most affected was bowel (7 patients), followed by the liver and skin, with 5 and 4 patients, respectively. In the analysis, we observed an increase in the survival of patients who developed GVHD ( $p=0.35$ ). Chronic GVHD occurred in 11 patients, the organ most affected was liver (7 patients), followed by skin (6 patients), bowel (4 patients), and lung ( 2 patients). There was an increase in survival relative to the presence of chronic GVHD ( $\mathrm{p}=0.13)$. One patient died because of chronic GVHD.

\section{Discussion}

The main indication for HSCT in children in our country continues to be ALL in second remission; many of 
these children have received first-line chemotherapy regimens and intense re-induction schemes, which usually generate acute and chronic systemic toxicities, including an effect on their nutritional status [18] [19] [23] [24]. The sum of the previously stated factors increases transplant-related morbidity-mortality (TRM) in these children, particularly in those who need an intense conditioning regimen to control their disease, schemes in which TBI therapy plays an important role.

Total body irradiation remains an important part of conditioning regimens in patients undergoing hematopoietic cell transplantation. Several randomized trials have shown that the administration of total body irradiation is superior to those regimens without it. The importance of radiotherapy sensitivity to leukemic cells is based on cells developing resistance to different chemotherapy agents, as well as on plasma clearance, and the sanctuaries do not represent a limited therapeutic factor [24] [25].

There are several reports that demonstrate the value of TBI as part of the conditioning scheme in patients with ALL. TBI has proven to eradicate leukemic cells and favors grafting, thus becoming an essential part of the therapeutic management. Given this new therapy modality, there are 2 important issues to consider-the lower TBI dose required to continue the effect on HSCT in ALL patients to lower potential adverse events and the vast history of this therapeutic regimen in pediatric patients worldwide.

To diminish the associated risks and/or complications secondary to full doses in conventional TBI, the trend is to use low-dose TBI regimens. However, there is no agreement regarding the ideal low dose of irradiation without compromising the overall survival in these children. It is well established that, in the short term, acute toxicity can significantly be reduced [10]-[13]; however, in the long term, particularly with chronic GVHD, the end results are less clear [26]. It could be that this approach to low-dose TBI toxicity is due to the selection of children with ALL.

Most of these patients were previously treated with chemotherapy and/or multiple complications, including severe infections, organ dysfunction or the use of peripheral blood stem cells [27].

This study demonstrates that the low-dose TBI regimen (600 cGy, fractioned) continues its therapeutic effect, boosting grafting and diminishing relapses without higher adverse effects. As documented by several authors, the source of hematopoietic stem cells was demonstrated to be a prognostic factor. In this study, we demonstrated that, for the children who received stem cells from peripheral blood, the cumulative survival was $60 \%$ compared with $40 \%$ for children with stem cells from umbilical cord blood. Additionally, a higher mortality rate was observed in patients who received stem cells from the umbilical cord (71.4\%) compared with $28 \%$ in children who were transplanted with stem cells from peripheral blood. Inagaki et al. [26] evaluated 55 patients with ALL in second remission and concluded that the source of hematopoietic stem cells did not cause any impact in the event-free survival of these patients.

However, a limiting factor of the current study was the effects of TBI on growth and the endocrine system. Therefore, it is necessary to evaluate in long term our approach with low-dose TBI, and determine if this dose not only produces a low rate of toxicity but also can produce an adequate antileukemic effect.

Currently, different groups are evaluating new conditioning regimens with chemotherapy and without TBI. This includes busulfan combined with other agents. Recently, the use of treosulfan appears to offer promising results for ALL [27].

\section{Conclusion}

TBI fractioned dose of 600 cGy diminishes the acute toxicity in children with ALL who were submitted to HSCT. However, the rate of GVH disease was not reduced. There is a need to evaluate this approach further to offer the lowest morbidity in children with ALL who underwent this treatment procedure.

\section{Declaration of Interest}

There is NO financial and personal relationship of any of the authors with any person and/or organization that influenced the current work. Therefore the Conflict of Interest is not present.

\section{References}

[1] Olaya-Vargas, A. (2012) Trasplante de Células Progenitoras Hematopoyéticas en Pediatría. Principios Básicos. Primera Edición, Editores de Textos Mexicanos, México. 
[2] Apperley, E., Carreras, E. and Gluckman, E. (2012) Hematopoietic Stem Cell Transplantation. 6th Edition, The EBMT Handbook, Geneva.

[3] Appelbaum, F.R., Forman, S.J., Negrin, R.S. and Blume, K.G. (2004) Hematopoietic Stem Cell Transplantation. 4th Edition, Wiley Blackwell Publishing.

[4] Rivera-Luna, R., Shalkow-Klincovstein, J., Velasco-Hidalgo, L., Cardenas-Cardos, R., Zapata-Tarrés, M., OlayaVargas, A., Aguilar-Ortiz, M.R., Altamirano-Alvarez, E., Correa-Gonzalez, C., Zanchez-Zubieta, F. and PantojaGuillen, F. (2014) Descriptive Epidemiology in Mexican Children with Cancer under an Open National Public Health Insurance Program. BMC Cancer, 14, 790-798. http://dx.doi.org/10.1186/1471-2407-14-790

[5] Wong, J.Y., Forman, S., Somlo, G., Rosenthal, J., Liu, A., Schultheiss, T., Radany, E., Palmer, J. and Stein, A. (2013) Dose Escalation of Total Marrow Irradiation With Concurrent Chemotherapy in Patients With Advanced Acute Leukemia Undergoing Allogeneic Hematopoietic Cell Transplantation. International Journal of Radiation Oncology Biology, Physics, 85, 148-156. http://dx.doi.org/10.1016/j.ijrobp.2012.03.033

[6] Kal, H., Van Kempen-Harteveld, M.L., Heijenbrok-Kal, M.H. and Struikmans, H. (2006) Biologically Effective Dose in Total-Body Irradiation and Hematopoietic Stem Cell Transplantation. Strahlentherapie und Onkologie, 182, 672679. http://dx.doi.org/10.1007/s00066-006-1528-6

[7] Park, J., Choi, E.K., Kim, J.H., Lee, S.W., Song, S.Y., Yoon, S.M., Kim, Y.S., Kim, S.S., Park, J.H., Park, J. and Ahn, S.D. (2014) Effects of Total Body Irradiation-Based Conditioning on Allogeneic Stem Cell Transplantation for Pediatric Acute Leukemia: A Single-Institution Study. Radiation Oncology Journal, 32, 198-207.

http://dx.doi.org/10.3857/roj.2014.32.3.198

[8] Van Kempen-Harteveld, M.L., Brand, R., Kal, H.B., Verdonck, L., Hofman, P., Schattenberg, A., Van der Maazen, R., Corneissen, J., Eijkenboom, W., van der Lelie, J., Oldenburger, F., Barge, R., van Biezen, A., Vossen, J., Noordijk, E. and Struikmans, H. (2008) Results of Hematopoietic Stem Cell Transplantation after Treatment with Different HighDose Total-Body Irradiation Regimens in Five Dutch Centers. Int. J. Radiation Oncology Biol. Phys., 71, 1444-1454. http://dx.doi.org/10.1016/j.ijrobp.2007.11.072

[9] Yan Yanagisawa, R., Nakazawa, Y., Sakashita, K., Tanaka, M., Shikama, N., Kamijo, T., Shiohara, M. and Koike, K. (2009) Low Toxicity of a Conditioning with 8-Gy Total Body Irradiation, Fludarabine and Cyclophosphamide as Preparative Regimen for Allogeneic Hematopoietic Stem Cell Transplantation in Pediatric Hematological Malignancies. Pediatric Transplantation, 13, 737-745. http://dx.doi.org/10.1111/j.1399-3046.2008.01065.x

[10] Gorak, E., Geller, N., Srinivasan, R., Espinoza-Delgado, I., Donohue, T., Barrett, A.J., Suffredini, A. and Childs, R. (2008) Engraftment Syndrome after Nonmyeloablative Allogeneic Hematopoietic Stem Cell Transplantation: Incidence and Effects on Survival. Biology of Blood and Marrow Transplantation, 11, 542-550.

[11] Hamidieh, A., Kargar, M., Jahani, M., Alimoghaddam, K., Bahar, B., Mousavi, S.A., Iravani, M., Jalali, A., Jalili, M. and Ghavamzadeh, A. (2012) The Outcome of Allogeneic Hematopoietic Stem Cell Transplants without Total Body Irradiation in Pediatric Patients with Acute Lymphoblastic Leukemia: Single Center Experience. Journal of Pediatric Hematology/Oncology, 34, 101-107. http://dx.doi.org/10.1097/mph.0b013e31824435a1

[12] Sato, N., Furukawa, T., Kuroha, T., Hashimoto, S., Masuko, M., Takahashi, H., Yano, T., Abe, T., Fuse, I., Koike, T., Kishi, K. and Aizawa, Y. (2004) High-Dose Cytosine Arabinoside and Etoposide with Total Body Irradiation as a Preparatory Regimen for Allogeneic Hematopoietic Stem-Cell Transplantation in Patients with Acute Lymphoblastic Leukemia. Bone Marrow Transplantation, 34, 299-303. http://dx.doi.org/10.1038/sj.bmt.1704575

[13] Davies, S.M., Ramsay, N.K., Klein, J.P., Weisdorf, D.J., Bolwell, B., Cahn, J.Y., Camitta, B.M., Gale, R.P., Giralt, S., Heilmann, C., Henslee-Downey, P.J., Herzig, R.H., Hutchinson, R., Keating, A., Lazarus, H.M., Milone, G.A., Neudorf, S., Perez, W.S., Powles, R.L., Prentice, H.G., Schiller, G., Socié, G., Vowels, M., Wiley, J., Yeager, A. and Horowitz, M.M. (2000) Comparison of Preparative Regimens in Transplants for Children with Acute Lymphoblastic Leukemia. Journal of Clinical Oncology, 18, 340-347.

[14] Pui, C.-H., Relling, M.V. and Downing, J.R. (2004) Mechanisms of Disease: Acute Lymphoblastic Leukemia. N Engl J Med., 350, 1535-1548. http://dx.doi.org/10.1056/NEJMra023001

[15] Schrauder, A., von Stackelberg, A., Schrappe, M., Cornish, J. and Peters, C., ALL-BFM Study Group; EBMT PD WP; I-BFM Study Group (2008) Allogeneic Hematopoietic SCT in Children with ALL: Current Concepts of Ongoing Prospective SCT Trials. Bone Marrow Transplantation, 41, 71-74. http://dx.doi.org/10.1038/bmt.2008.58

[16] Petropoulos, D., Worth, L.L., Mullen, C.A., Madden, R., Mahajan, A., Choroszy, M., Ha, C.S., Champlin, R.C. and Chan, K.W. (2006) Total Body Irradiation, Fludarabine, Melphalan, and Allogeneic Hematopoietic Stem Cell Transplantation for Advanced Pediatric Hematologic Malignancies. Bone Marrow Transplantation, 37, 463-467. http://dx.doi.org/10.1038/sj.bmt.1705278

[17] Aschan, J. (2007) Risk Assessment in Haematopoietic Stem Cell Transplantation: Conditioning. Best Practice \& Research Clinical Haematology, 20, 295-310. http://dx.doi.org/10.1016/j.beha.2006.09.004 
[18] Girgis, M., Hallemeier, C., Blum, W., Brown, R., Lin, H.S., Khoury, H., Goodnough, L.T., Vij, R., Devine, S., Wehde, M., Postma, S., Oza, A., Dipersio, J. and Adkins, D. (2005) Chimerism and Clinical Outcomes of 110 Recipients of Unrelated Donor Bone Marrow Transplants Who Underwent Conditioning with Low-Dose, Single-Exposure Total Body Irradiation and Cyclophosphamide. Blood, 105, 3035-3041. http://dx.doi.org/10.1182/blood-2003-07-2346

[19] Hallemeier, C., Girgis, M., Blum, W., Brown, R., Khoury, H., Goodnough, L.T., Vij, R., Devine, S., Wehde, M., Postma, S., Lin, H.S., Dipersio, J. and Adkins, D. (2004) Outcomes of Adults with Acute Myelogenous Leukemia in Remission Given 550 cGy of Single-Exposure Total Body Irradiation, Cyclophosphamide, and Unrelated Donor Bone Marrow Transplants. Biology of Blood and Marrow Transplantation, 10, 310-319. http://dx.doi.org/10.1016/j.bbmt.2003.12.002

[20] Gupta, T., Kannan, S., Dantkale, V. and Laskar, S. (2011) Cyclophosphamide plus Total Body Irradiation Compared with Busulfan plus Cyclophosphamide as a Conditioning Regimen Prior to Hematopoietic Stem Cell Transplantation in Patients with Leukemia: A Systematic Review and Meta-Analysis. Hematology/Oncology and Stem Cell Therapy, 4, 17-29. http://dx.doi.org/10.5144/1658-3876.2011.17

[21] Kalaycio, M., Bolwell, B., Rybicki, L., Absi, A., Andresen, S., Pohlman, B., Dean, R., Sobecks, R. and Copelan, E. (2011) Bu-vs-TBI Based Conditioning for Adult Patients with ALL. Bone Marrow Transplant, 46, 1413-1417. http://dx.doi.org/10.1038/bmt.2010.314

[22] Tracey, J., Zhang, M.J., Thiel, E., Sobocinski, K.A. and Eapen, M. (2013) Transplantation Conditioning Regimens and Outcomes after Allogeneic Hematopoietic Cell Transplantation in Children and Adolescents with Acute Lymphoblastic Leukemia. Biology of Blood and Marrow Transplantation, 19, 255-259. http://dx.doi.org/10.1016/j.bbmt.2012.09.019

[23] Li, D.Z., Kong, P.Y., Sun, J.G., Wang, X.X., Li, G.H., Zhou, Y.B. and Chen, Z.T. (2012) Comparison of Total Body Irradiation before and after Chemotherapy in Pretreatment for Hematopoietic Stem Cell Transplantation. Cancer Biotherapy and Radiopharmaceuticals, 27, 119-123. http://dx.doi.org/10.1089/cbr.2011.1041

[24] Mohty, B. and Mohty, M. (2011) Long-Term Complications and Side Effects after Allogeneic Hematopoietic Stem Cell Transplantation: An Update. Blood Cancer Journal, 1, e16. http://dx.doi.org/10.1038/bcj.2011.14

[25] Mohty, M., Malard, F. and Savani, B. (2015) High Dose Total Body Irradiation and Myeloablative Conditioning before Allogenic Hematopoietic Cell Transplantation: Time to Rethink? Biology of Blood and Marrow Transplantation, 21, 620-624. http://dx.doi.org/10.1016/j.bbmt.2014.09.010

[26] Inagaki, J., Fukano, R., Noguchi, M., Kurauchi, K., Tanioka, S. and Okamura, J. (2015) Hematopoietic Stem Cell Transplantation Following Unsuccessful Salvage Treatment for Relapsed Acute Lymphoblastic Leukemia in Children. Pediatric Blood \& Cancer, 62, 674-679. http://dx.doi.org/10.1002/pbc.25353

[27] ten Brink, M.H., Zwaveling, J., Swen, J.J., Bredius, R.G., Lankester, A.C. and Guchelaar, H.J. (2014) Personalized Busulfan and Treosulfan Conditioning for Pediatric Stem Cell Transplantation: The Role of Pharmacogenetics and Pharmacokinetics. Drug Discovery Today, 19, 1572-1586. http://dx.doi.org/10.1016/j.drudis.2014.04.005

\section{Submit or recommend next manuscript to SCIRP and we will provide best service for you:}

Accepting pre-submission inquiries through Email, Facebook, LinkedIn, Twitter, etc.

A wide selection of journals (inclusive of 9 subjects, more than 200 journals)

Providing 24-hour high-quality service

User-friendly online submission system

Fair and swift peer-review system

Efficient typesetting and proofreading procedure

Display of the result of downloads and visits, as well as the number of cited articles

Maximum dissemination of your research work

Submit your manuscript at: http://papersubmission.scirp.org/ 